OPEN ACCESS

Edited by: Ara Monadjem, University of Eswatini, Eswatini

Reviewed by: Maria João Ramos Pereira, Federal University of Rio Grande do

Sul, Brazil

James Austin,

University of Florida, United States

*Correspondence: Ingrid de Mattos mtt.ingrid@gmail.com

Specialty section:

This article was submitted to Biogeography and Macroecology,

a section of the journal Frontiers in Ecology and Evolution

Received: 31 July 2021 Accepted: 15 November 2021 Published: 23 December 2021

Citation:

Mattos I, Zimbres $B$ and Marinho-Filho J (2021) Habitat Specificity Modulates the Response

of Small Mammals to Habitat Fragmentation, Loss, and Quality in a Neotropical Savanna.

Front. Ecol. Evol. 9:751315. doi: 10.3389/fevo.2021.751315

\section{Habitat Specificity Modulates the Response of Small Mammals to Habitat Fragmentation, Loss, and Quality in a Neotropical Savanna}

\author{
Ingrid de Mattos $^{1 *}$, Bárbara Zimbres ${ }^{2}$ and Jader Marinho-Filho ${ }^{1}$ \\ ${ }^{1}$ Departamento de Zoologia, Instituto de Ciências Biológicas, Universidade de Brasilia, Brasilia, Brazil, ${ }^{2}$ Amazon \\ Environmental Research Institute (IPAM), Brasilia, Brazil
}

Landscape conversion of natural environments into agriculture and pasture are driving a marked biodiversity decline in the tropics. Consequences of fragmentation might depend upon habitat amount in the landscape, while the quality of remnants can also affect some species. These factors have been poorly studied in relation to different spatial scales. Furthermore, the impacts of these human-driven alterations may go beyond species loss, possibly causing a loss of ecosystem function and services. In this study, we investigated how changes in landscape configuration (patch size and isolation), habitat loss (considering a landscape gradient of 10, 25, and $40 \%$ of remnant forest cover), and habitat quality (forest structure) affect small mammal abundance, richness, taxonomic/functional diversity, and species composition in fragmented landscapes of semideciduous forests in the Brazilian Cerrado. Analyses were performed separately for habitat generalists and forest specialists. We live-trapped small mammals and measured habitat quality descriptors four times in 36 forest patches over the years 2018 and 2019, encompassing both rainy and dry seasons, with a total capture effort of 45,120 trap-nights. Regression analyses indicated that the effect of landscape configuration was not dependent on the proportion of habitat amount in the landscape to determine small mammal assemblages. However, both patch size and habitat loss impacted different aspects of the assemblages in distinct ways. Smaller patches were mainly linked to an overall increase in small mammal abundance, while the abundance of habitat generalists was also negatively affected by habitat amount. Generalist species richness was determined by the proportion of habitat amount in the landscape. Specialist richness was influenced by patch forest quality only, suggesting that species with more demanding habitat requirements might respond to fragmentation and habitat loss at finer scales. Taxonomic or functional diversity were not influenced by landscape structure or habitat quality. However, patch size and habitat amount in the landscape were the major drivers of change in small mammal species composition in semideciduous forests in the Brazilian savanna.

Keywords: Cerrado, landscape structure, forest structure, rodents, marsupials, functional diversity 


\section{INTRODUCTION}

Habitat loss and fragmentation are the main drivers of biodiversity decline on Earth (Pardini et al., 2010; Haddad et al., 2015; Hanski, 2015; Laurance et al., 2018). In the tropics, these landscape alterations result mostly from the conversion of natural environments into agriculture and pasture (Fearnside, 2001; Gibbs et al., 2010; Peres et al., 2010; Françoso et al., 2015; Strassburg et al., 2017). These human-driven changes may affect species abundance, richness, and diversity (Andren, 1994; Fahrig, 2003; Laurance et al., 2011; Hanski, 2015; Melo, 2015; Bovendorp et al., 2019). Additionally, ecological traits might be filtered out, which might drive communities to biotic homogenization (Olden et al., 2004; Gámez-Virués et al., 2015; Melo, 2015; Almeida-Gomes et al., 2019), leading to changes in ecosystem function and forest dynamics (see Laurence et al., 2000; Haddad et al., 2015; Laurance et al., 2018). Therefore, understanding the impacts of habitat conversion not only on taxonomic diversity, but also on functional diversity (i.e., the degree of functional difference among species in a community) (Petchey and Gaston, 2006) allows a broader comprehension of the consequences of species loss on ecosystem functioning and stability (Petchey and Gaston, 2006). Conservation strategies should be more effective in maintaining ecosystem services if they also consider the functional dimension of biodiversity (Cadotte et al., 2011; Freitas and Mantovani, 2018).

Habitat amount in the landscape is an important predictor of species persistence in altered landscapes (Andren, 1994; Fahrig, 2003, 2013; Melo et al., 2017). However, the effects of fragmentation may vary depending on landscape context (Andren, 1994; Pardini et al., 2010; Villard and Metzger, 2014). In landscapes with high habitat cover, migration among patches are elevated enough to maintain high overall species abundance and richness, because of the proximity between fragments, irrespective of patch size (Pardini et al., 2010). As habitat loss advances, the relative importance of patch size and isolation to explain species loss and population declines increases (Andren, 1994; Villard and Metzger, 2014). Consequently, the effects of landscape configuration on species richness and abundance should be evident when there are intermediate amounts of habitat in the landscape (Pardini et al., 2010; Martensen et al., 2012; Villard and Metzger, 2014).

In severely eroded landscapes, however, connectivity is jeopardized enough that metapopulations can no longer persist, due to high extinction and low colonization rates (Lande, 1987; Andren, 1994). Under this condition, even large patches can present local extinctions due to increasing isolation, which renders them vulnerable to stochastic events. Any additional loss of native cover at the landscape scale might have greater impact on extinction and colonization probabilities (With and King, 1999; Fahrig, 2003). Therefore, no relationship between species richness and patch size would be expected (Pardini et al., 2010).

Within these diverse spatial dynamics, the interaction between patch and matrix can influence the ecological consequences of landscape alterations for different species (Prevedello and Vieira, 2010; Newmark et al., 2014; Wilson et al., 2016). Also, deterioration of patch habitat quality resulting from landscape conversion may contribute to species loss and changes in species composition (Tabarelli and Gascon, 2005; Carrete et al., 2009; Delciellos et al., 2016; Zimbres et al., 2017; Hannibal et al., 2020), because habitat complexity and heterogeneity are well known to influence biodiversity (Fahrig et al., 2011; Lesak et al., 2011; Ke et al., 2018; Laurance et al., 2018). Despite the important role of habitat quality in regulating spatial dynamics in fragmented landscapes and influencing species distribution patterns, few studies have investigated this subject in comparison to classical spatial approaches (Mortelliti et al., 2010). Moreover, knowledge on this matter can improve considerably the effectiveness of management strategies applied to the conservation of remnants, their diversity, and the ecosystem services provided by them (Tabarelli and Gascon, 2005). This is especially critical for the Brazilian environmental policies, because most of the protected areas in the country consists of legally required forest areas set aside within private landholdings (Galleti et al., 2010).

Non-flying small mammals (Rodentia and Didelphimorphia) are abundant, diverse, and perform key roles in the ecosystems as seed/seedling predators, seed dispersers, prey for many predators, and secondary consumers (Brown et al., 2001; Bisceglia et al., 2011; Ribeiro et al., 2019). Additionally, they respond to microhabitat structure (Kajin and Grelle, 2012), to resource diversity/availability (Bergallo and Magnusson, 1999; Previtali et al., 2009; Camargo et al., 2019a), and are sensitive to environmental and landscape changes (Pardini et al., 2010; Melo et al., 2017; Hannibal et al., 2018). These characteristics make them potential indicators of environmental quality (Bonvicino et al., 2002), and an ideal group to assess human-driven landscape impacts on biodiversity.

In this study, we investigated how changes in landscape configuration (i.e., patch size and isolation), habitat loss (considering a gradient of 10, 25, and $40 \%$ of remnant habitat amount), and habitat quality (i.e., forest structure) affect small mammal abundance, richness, taxonomic/functional diversity, and species composition in fragmented landscapes of semideciduous forests in the Brazilian Cerrado. We expected the effect of patch size on community metrics to be dependent on the landscape context in terms of overall habitat amount. In landscapes with intermediate levels of habitat amount, patch size effects should be stronger, especially for forestdependent species (Pardini et al., 2010; Villard and Metzger, 2014; Melo, 2015). Yet, in more degraded landscapes (10\% of habitat amount) and in more conserved ones (40\%), we expected to find no patch size effects on abundance, richness, and diversity, but only a positive effect of habitat amount. On the other hand, we predicted that generalist species should not respond to patch size, neither to habitat amount in the landscape, or be affected by patch size alone in the most degraded landscape (10\%) (Pardini et al., 2010). Regarding habitat quality (here represented by forest structure features), we foresaw that more conserved patches (i.e., with higher structural complexity and heterogeneity) should harbor more species, and with higher abundance, mainly for forest specialists. Therefore, assemblages in more complex forests should be more diverse taxonomically and functionally (Zimbres et al., 2017). 
Finally, we expected species composition to vary across the landscape structure gradient, also according to changes in habitat quality (i.e., forest structure). Rare species, forest specialists, with higher sensitiveness to environmental alterations would be more associated with larger patches and/or landscapes with higher levels of habitat amount, as well as to more structurally complex forests (Melo, 2015; Hannibal et al., 2020). On the other hand, tolerant and generalist species would be more associated with smaller and isolated patches, lower habitat amount in the landscape, and low habitat quality (Melo, 2015).

\section{MATERIALS AND METHODS}

\section{Study Area}

We conducted the study in the Brazilian Cerrado, a biodiversity hotspot (Myers et al., 2000). This neotropical savanna is one of the richest savannas in the world (Klink et al., 2005; Ribeiro and Walter, 2008), and presents high environmental heterogeneity, comprising different vegetation physiognomies such as open grasslands, typical savannas, and forests (Oliveira-Filho and Ratter, 2002; Ribeiro and Walter, 2008). Seasonal forests were once probably the most extensive forest type within this biome (Oliveira-Filho and Ratter, 2002). Since it occurs on highly fertile soils, and harbors economically valuable plant species, it was the first vegetation physiognomy to be converted into crop fields and pastures, also being exploited by logging activities (Murphy and Lugo, 1986; Oliveira-Filho and Ratter, 2002; Miles et al., 2006). It is still a poorly studied vegetation type, and has been neglected in terms of conservation efforts (Scariot and Vieira, 2006; Prieto-Torres et al., 2021).

Our study sites were located in remnants of semideciduous seasonal forests in a highly deforested portion of the Cerrado, in Central Brazil. The study areas comprised three landscapes of $\sim 15,000$ ha with different levels of remnant habitat amount ( 10, 25, and 40\%). In each landscape, we sampled 12 forest patches (totaling 36 sampling sites) (Figure 1). Remnants ranged from 2.41 to 1440 ha (Supplementary Table 1). Sampling site choice was based on (1) the highest variation in patch size possible within each landscape; (2) ease of access; (3) landowners' permissions. Sampling patches were located in the municipalities of Abadiânia $\left(16^{\circ} 2^{\prime} 51^{\prime \prime} \mathrm{S} 48^{\circ} 51^{\prime} 44^{\prime \prime} \mathrm{W}\right)$, Jesúpolis $\left(15^{\circ} 57^{\prime} 05^{\prime \prime} \mathrm{S}\right.$ $\left.49^{\circ} 22^{\prime} 26^{\prime \prime} \mathrm{W}\right)$, Jaraguá $\left(15^{\circ} 44^{\prime} 31^{\prime \prime} \mathrm{S} 49^{\circ} 20^{\prime} 6^{\prime \prime} \mathrm{W}\right)$, Ouro Verde de Goiás $\left(16^{\circ} 13^{\prime} 13^{\prime \prime} \mathrm{S} 49^{\circ} 11^{\prime} 36^{\prime \prime} \mathrm{W}\right)$, Pirenópolis $\left(15^{\circ} 53^{\prime} 06.40^{\prime \prime}\right.$ S $\left.49^{\circ} 10^{\prime} 46.29^{\prime \prime} \mathrm{W}\right)$, and São Francisco de Goiás $\left(15^{\circ} 55^{\prime} 51^{\prime \prime} \mathrm{S}\right.$ $\left.49^{\prime} 15^{\prime} 2^{\prime \prime} \mathrm{W}\right)$, in the central portion of the state of Goiás, Brazil. In this region, the matrix is composed mainly of pasture, but there are also agricultural areas (such as crop fields and/or banana plantations), and few patches of native savanna vegetation. Sampling sites were located in the Legal Reserves of private farms, which are natural vegetation areas all landowners are legally obliged to set aside. Also, there were three sites adjacent to conservation units (Reserva Particular de Patrimônio Natural Vaga Fogo Farm, Pirenópolis - GO, and Parque Estadual da Serra de Jaraguá, Jaraguá - GO).

The climate is classified as Aw according to Köppen, with two well defined seasons (hot/wet summers from October to March, and dry/cold winters from April to September). To minimize differences in species composition between sampling sites, maximum distance between landscapes did not exceed $100 \mathrm{~km}$, and were located in the same river basin (Basin of Tocantins-Araguaia river).

\section{Small Mammal Survey}

In each of the 36 sampled patches, we established a trapping line of $200 \mathrm{~m}$, located $30 \mathrm{~m}$ from patch edges to minimize edge effects. Each line had 20 trap stations, placed every $10 \mathrm{~m}$, with four live traps each, where half were set on the ground, and half in the understory ( $1.5 \mathrm{~m}$ to $3 \mathrm{~m}$ height), totaling 80 traps per patch. Every station had a Tomahawk ${ }^{\circledR}(300 \times 160 \times 160 \mathrm{~mm})$ and a small Sherman ${ }^{\circledR}(250 \times 80 \times 90 \mathrm{~mm})$ on the ground, and a large Sherman $(300 \times 80 \times 90 \mathrm{~mm})$ and a small one in the understory, except for the first and last trap stations, where we replaced a Tomahawk trap by a large Sherman. Understory traps were strapped with a wire onto wooded vines or more horizontal trunks of tree trunks that were connected to the forest canopy, avoiding isolated trees. The study was conducted over the years 2018 and 2019, in the following periods: rainy-dry season (April to June 2018), dry-rainy season (August to October 2018), rainy (February to April 2019), and dry season (June to August 2019). Captures occurred during four consecutive nights per field campaign, resulting in an effort of 1,280 trap-nights per patch and 45,120 trap-nights in total.

Traps were baited with a mixture of peanut butter, corn powder, sardine, and banana. Captured animals were identified and marked with numbered ear-tags. They were released in the same trap location where they were captured. Voucher specimens were collected and will be held in the Mammal Collection of the Department of Zoology, University of Brasília (UnB, Brasília, Brazil). All procedures followed the guidelines of the American Society of Mammalogists for the use of wild animals in research (Sikes and The Animal Care and Use Committee of the American Society of Mammalogists, 2016).

\section{Landscape Structure}

Landscape types were categorized based on the 2016 land use and land cover map from the MapBiomas ${ }^{1}$ project, collection 4.0, which classifies Landsat satellite imagery at a 30-m resolution. The temporal mismatch between the land cover map from MapBiomas and the field campaigns should not be important, as the study sites are within a relatively consolidated landscape in terms of human occupation. Landscape choice was based on the proportion of five land cover classes: forest, savanna, agriculture, pasture, and mosaic of agriculture and pasture.

Landscape structure was evaluated as: patch size (ha); mean patch isolation (as the mean distance to all nearest neighbor patches in a $1 \mathrm{~km}$ radius buffer); and proportion of habitat amount available in each landscape context $[10,25$, and $40 \%$ of natural cover (forest plus savanna) as shown in Figure 1]. These metrics were calculated using the Patch Analyst extension in ArcGis 10.2.

\section{Habitat Quality}

We considered patch quality as habitat properties that might have an impact on population parameters such as survival

\footnotetext{
${ }^{1}$ http://mapbiomas.org
} 


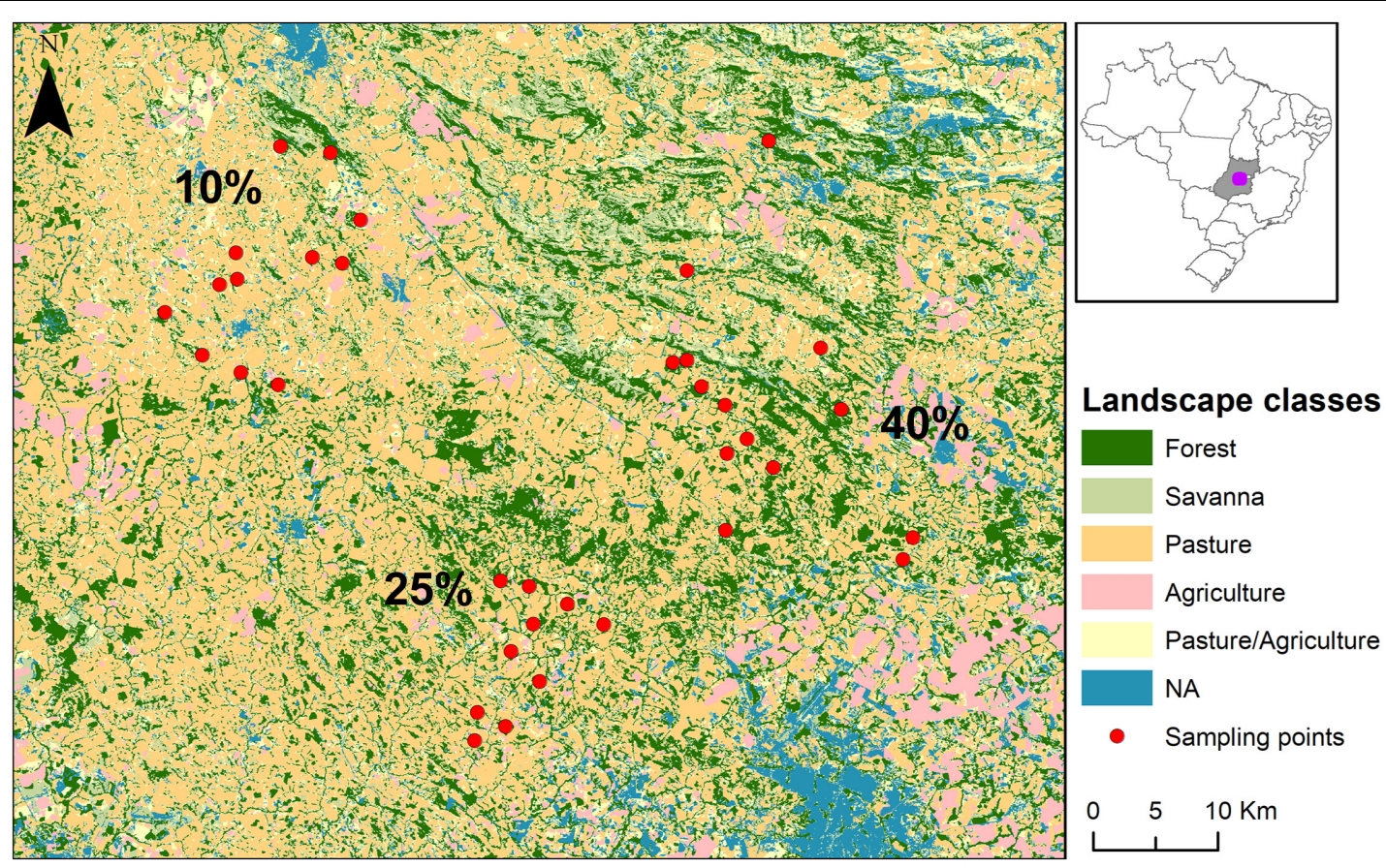

FIGURE 1 | Landscapes of 15,000 ha with 10, 25, and $40 \%$ of habitat amount (including both forest and savanna), and the sampled patches (red dots) in central state of Goiás, Brazil (highlighted in gray in the inset map). Patches located in the western portion of the map are within the landscape with $10 \%$ of remnant habitat amount; southern patches correspond to the landscape with 25\%; and the eastern patches are in the landscape with $40 \%$ of habitat amount.

and fecundity (Mortelliti et al., 2010). To that end, we selected environmental variables revealed by other studies as important to small mammal occurrence and habitat use, which can potentially affect population parameters and individual condition, influencing species coexistence (Pardini et al., 2005; Ribeiro, 2015; Delciellos et al., 2016, 2018; Camargo et al., 2018; Hannibal et al., 2018, 2020). These variables describe habitat heterogeneity and forest complexity.

At each patch,we sampled descriptors of habitat quality in ten $4 \times 4$-m plots located every $20 \mathrm{~m}$ along the $200-\mathrm{m}$ transect line. Each plot corner was marked by a colored flagging tape for the plot to be re-visited during the study. To evaluate forest structure, we measured the following variables inside each plot: (1) Canopy cover, as the proportion of closed pixels from a photograph taken with a digital camera in the center of each plot, using the software Image J. We took one picture per season and used mean values per patch; (2) Mean number of vines; (3) Mean tree height $(\mathrm{m})$ of the closest four trees from the plot center, with circumference $\geq 16 \mathrm{~cm}$ at $30 \mathrm{~cm}$ height estimated with a $3-\mathrm{m}$ pole; (4) Basal area $\left(\mathrm{m}^{2}\right)$, estimated from the diameter at breast height $(\mathrm{DBH})$ from the same four previously measured trees; (5) Understory clutter (up to a 3-m height) (\%), estimated with a graduated $3-\mathrm{m}$ pole (with a graduation of $10 \mathrm{~cm}$ ) following Martins et al. (2017); (6) Litter volume $\left(\mathrm{cm}^{3}\right)$, estimated from litter material sampled in a $50 \times 50$ $\mathrm{cm}$ quadrat inside each plot (located in its superior left corner), following Santos Filho et al. (2008). We placed the collected litter inside a translucid graduated cylindric box (with a diameter of $28.2 \mathrm{~cm}$ ), and pressed down the material with a 1-kg weight, thus indicating the correspondent litter height on a scale of $120 \mathrm{~mm}$
(Supplementary Figure 1). Litter height (h) was then used to estimate cylinder volume according to $\mathrm{V}=\pi$. $(14.1)^{2} . \mathrm{h}$.

Cattle ranching is the main human activity in the study region, so we also estimated (7) Cattle intrusion to measure humandriven habitat alteration in forests. We classified intrusion level as an ordinated variable (0-4) based on incidence of footprints, cattle trampling, and dung presence in a $15-\mathrm{m}$ radius around each plot center. For this variable we used median plot values for each patch, while we used mean values for all the other variables.

\section{Functional Traits}

To assess species functional responses to habitat loss and fragmentation, as well as to habitat quality, we used morphological and behavioral traits related with habitat use and trophic habits, which might influence species tolerance to landscape alterations (Supplementary Table 2). We measured the following quantitative morphological traits in the field: (1) Tail length (mean tail length/mean body length), which is related to vertical use of space: longer tails are associated to more arboreal habits (Eisenberg and Wilson, 1981); (2) Hind foot width (mean width/mean length of hind foot), which is related with locomotion habits, and consequently with use of space: short and wider hind feet are associated with more arboreal habits, while longer and straight hind feet indicate more cursorial habits (Camargo et al., 2008; Vieira and de Camargo, 2012); (3) Body weight (g), a feature related with food resource use (influencing prey size consumed), metabolic costs (MacMillen, 1983), travel speed (Hirt et al., 2017), dispersal distance (Whitmee and Orme, 2013), trophic niche partitioning (Andreas et al., 2013), foraging behavior, and predation risk (Kotler and Brown, 1988); 
(4) Arboreality index (number of captures in understory/total number of captures), which measures the vertical use of space (Camargo et al., 2019b). As categorical variables, we classified the species based on information available in the literature according to: (5) habitat specificity (forest specialists - species restricted to forest environments, or habitat generalists - species that inhabit forests as well as open areas, such as grasslands, savannas, and crop fields) following Bonvicino et al. (2002), Marinho-Filho et al. (2002), Pardini (2004), Bezerra et al. (2009), Cáceres et al. (2010), Oliveira and de Bonvicino (2011), Rossi et al. (2011), Gomes et al. (2015), and Ribeiro (2015) (Supplementary Table 2); and finally the multichoice binary variable (6) Diet representing a combination of the following trophic guilds: insectivore, frugivore, granivore, and omnivore (Paglia et al., 2012; Shiels et al., 2014; Riofrío-Lazo and Páez-Rosas, 2015).

\section{Data Analyses Community Metrics}

We evaluated species richness [with Chaol estimator (Colwell et al., 2012)], and abundance (as the total number of individuals captured in each patch) separately for forest specialists and habitat generalists. Considering all species together, we estimated taxonomic species diversity with the true diversity Shannon Index $\left(\exp \left(\mathrm{H}^{\prime}\right)\right]$ (Jost, 2006), and functional diversity (FD) was evaluated as the Rao's quadratic entropy (Q). It measures functional distance between pairs of individuals based on the selected functional traits, and incorporates species abundances (Botta-Dukát, 2005), besides being weakly influenced by species richness (Laliberté and Legendre, 2010; Pavoine and Bonsall, 2011; Dias et al., 2013). We used Gower distance to estimate FD, since we had continuous, categorical, and binary traits (Podani and Schmera, 2006; de Bello et al., 2010). Taxonomic metrics were calculated using the vegan package (Oksanen et al., 2019) in $\mathrm{R}$, while functional diversity was estimated with the FD package (Laliberté et al., 2014).

\section{Community Metrics and the Effects of Fragmentation and Habitat Loss}

To evaluate the relative effects of patch size and patch isolation according to landscape habitat amount, we performed regression analyses with generalized linear models (GLMs) using the lme4 package (Bates et al., 2015). GLMs were used to accommodate residual deviations from normality. Also, according to the response variables evaluated and model residual dispersion, we used different distribution families (Gaussian, Gamma, Poisson, and Negative Binomial) (Zuur et al., 2009). To determine which variables influences our response variables the most, nested models were compared by likelihood ratio tests (LRT). The significance of explanatory variables was given by Deviance and p-values, based on $\chi^{2}$ tests. For all global models, we investigated spatial autocorrelation in the model residuals with Moran's I associated with bubble plots from the sp package in R (Pebesma and Bivand, 2005). Also, we checked for multicollinearity between predictors using the variance inflation factor (VIF) in all global models (Zuur et al., 2007). During model fitting, we log-transformed patch size to improve the homoscedasticity of residuals (Zuur et al., 2007). Also, predictors were standardized (scaled to the $\mathrm{z}$-score) to ensure variables were at the same scale.
We tested for overdispersion with Pearson residuals in all global models and used Negative Binomial GLM to correct it whenever needed. We performed model validation by visual inspection of model residuals following Zuur et al. (2009).

\section{Community Metrics and Habitat Quality}

We evaluated the effects of habitat quality in community metrics following the same protocol described above using GLM. However, we first performed a principal component analysis (PCA) to reduce the data dimensionality of forest structure variables (Borcard et al., 2011). We used scores from PC1 and PC2 (summarizing $>50 \%$ of variable variation between sampling sites) as predictors in GLM models. Before running the PCA, we checked for multicollinearity between habitat variables, excluded those with Pearson correlations $>0.5$, and scaled variables to the $\mathrm{z}$-score.

\section{Species Composition, Landscape Structure, and Habitat Quality}

To evaluate whether changes in species composition were explained by the gradients of fragmentation and habitat loss, as well as by habitat quality, we applied a redundancy analysis (RDA) using the vegan package (Oksanen et al., 2019). We used a species abundance matrix with Hellinger transformation (Borcard et al., 2011) as the response variable, while patch size, patch isolation, proportion of habitat amount in the landscape, and PC1 and PC2 were input as scaled predictors. Moreover, global significance of the RDA model, significance of RDA axes, and significance of model terms (predictors) were tested with permutation tests based on 1000 randomizations (Borcard et al., 2011). Before running the model, we tested for spatial autocorrelation between species composition and geographic coordinates with Mantel correlograms based on 999 randomizations.

All analyses were conducted in $\mathrm{R}$ version 3.6.2 (R Core Team, 2019).

\section{RESULTS}

With a capture success of $4.56 \%$, we registered 1323 individuals, recaptured 735 times. Captures belonged to 15 species, five marsupial and 11 rodent species (Supplementary Table 1). The most abundant species in the study were the marsupials Gracilinanus agilis ( $n=840$ individuals, 63\% of total captures) and Didelphis albiventris $(n=134,10 \%)$, followed by the rodents Oecomys cleberi $(n=121,9.1 \%)$, and Rhipidomys macrurus $(n=70,5.2 \%)$ (Supplementary Table 1). The rarest species were the exotic european rodent Rattus rattus $(n=1)$ and Oligoryzomys nigripes $(n=1)$.

Regression models were not overdispersed, and most of them presented no spatial autocorrelation according to Moran's I test (Supplementary Table 3). However, whenever we detected spatial autocorrelation in model residuals, we did a visual inspection of residual dispersion (Zuur et al., 2009), associated with the visualization of bubble plots of the model's Pearson residuals and site coordinates. This led us to conclude that correlations were not linked directly to the spatial variation 
of the measured variables themselves, since there was no clear spatial pattern detected, overall small correlation values, and only a few sites presenting higher values. Correlations were thus considered second order correlations (stochastic or purely random) (Borcard et al., 2011). Therefore, we did not consider them important enough to compromise the global model, so we proceeded with the analyses.

\section{Community Metrics and the Effects of Fragmentation and Habitat Loss}

Regarding habitat generalist abundance, we found a negative effect of patch area $\left(\beta_{\log \text { (patch area) }}=-0.44 \pm 0.09\right.$; $\mathrm{df}=33$; $p=1.022 \times 10^{-5}$, Figure $\mathbf{2 A}$ and Supplementary Table 4) and a slighter significant negative effect of habitat amount in the landscape $\left(\beta_{\text {landscape }}=-0.24 \pm 0.09\right.$; df $=33 ; p=0.019$, Figure 2B and Supplementary Table 4). In other words, generalist species were more abundant in smaller patches and in landscapes with lower proportion of habitat amount. Concerning the abundance of forest specialists, GLM revealed only a negative effect of patch area irrespective of landscape habitat amount $\left(\beta_{\log (\text { patch area })}=-0.47 \pm 0.19 ; \mathrm{df}=34 ; p=0.007\right.$, Figure $2 \mathrm{C}$ and Supplementary Table 4).

In relation to estimated species richness, we found a positive effect of landscape habitat amount for habitat generalists, indicating more conserved landscapes presented more species regardless of patch size ( $\beta_{\text {landscape }}=-0.047 \pm 0.02$; df $=34$; $p=0.043$, Figure 2D and Supplementary Table 4). For forest specialists, we failed to detect any effect of landscape structure in estimated species richness (Supplementary Table 4).

Moreover, regression models indicated that variations in species diversity or in functional diversity were not explained by landscape structure (Supplementary Table 4).

\section{Community Metrics and Habitat Quality}

Raw variables describing habitat quality are shown in Supplementary Table 1. Considering forest structure, here used as habitat quality features, the only variable excluded from the dataset used in the PCA analyses due to multicollinearity was cattle intrusion level, since it was highly correlated with understory clutter $(r=-0.75)$. We compared the explanatory power of the PCA axes with and without the variable cattle
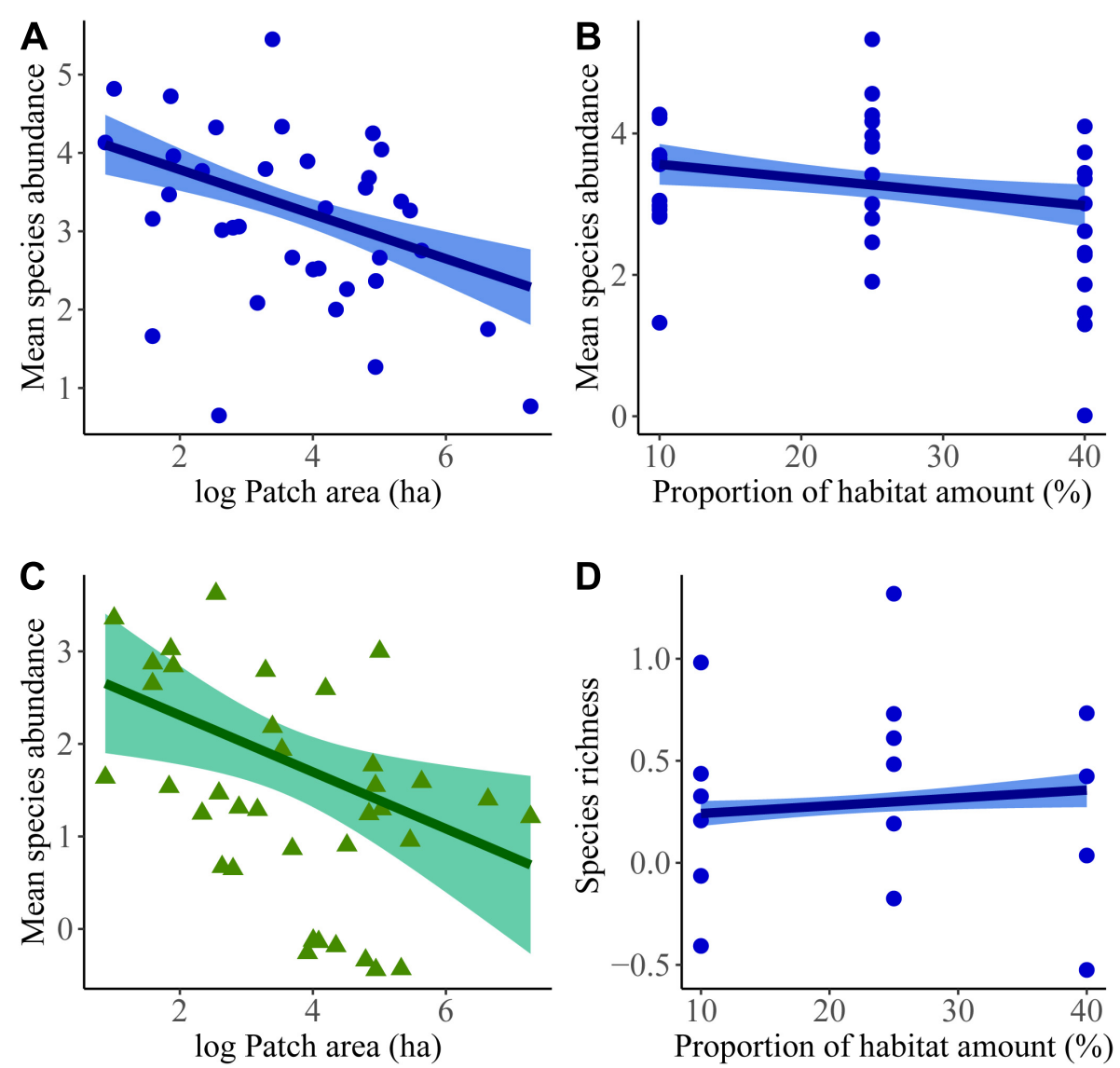

FIGURE 2 | Final regression models revealing the effects of landscape structure on small mammal community metrics in semideciduous forest patches in the Brazilian Cerrado, including: patch area (A) and proportion of habitat amount in the landscape (B) for the abundance of habitat generalists; the effect of patch area (C) for forest specialists, and the effect of proportion of habitat amount in the landscape (D) for generalist estimated species richness (Chao 1). Habitat generalists are represented in blue, forest specialists are shown in green. 
intrusion, and concluded that excluding it improved explanatory power. The first component of PCA (PC1) explained 29.55\% of data variation, while the second (PC2) explained $23.45 \%$. PC1 was more related to basal area and tree height (loading values $\geq 0.5$ ), while PC2 was more related with canopy cover (Supplementary Figure $\mathbf{2}$ and Supplementary Table 5). Therefore, PC1 axis represented a gradient of sites with shorter trees with lower basal area toward patches with taller trees with larger diameters. On the other hand, PC2 denoted a gradient of more open forests to more closed-canopy forests (Supplementary Figure 2).

Among all community metrics evaluated (abundance of generalist and specialist species, estimated richness for generalist and specialist species, species diversity, and FD), we only detected an effect of habitat quality on the richness of forest specialists. The number of forest specialists was positively associated with PC2, indicating that patches with higher canopy cover harbored more specialist species $\left(\beta_{\mathrm{PC} 2}=0.25 \pm 0.10 ; \mathrm{df}=34 ; p=0.018\right.$, Figure 3 and Supplementary Table 6).

\section{Species Composition, Landscape Structure, and Habitat Quality}

We found no spatial autocorrelation between species composition and the sites' geographic coordinates. The RDA representing the relationship between species composition, landscape structure, and habitat quality explained $26 \%$ of the variation of species abundance across sites (adjusted $R^{2}=0.13$; $p=0.001)$. In total, the first two axis explained $84 \%$ of data variation (RDA1 explained 55\%, and RDA2, 29\%). However, only the RDA1 axis was significant $(p=0.009)$, and among the explanatory variables, only patch area $(p=0.007)$, patch isolation $(p=0.018)$, and landscape habitat amount $(p=0.006)$ were significant.

Evaluating the RDA triplot (Figure 4) together with the significance of axes and predictors, we observed that both evaluated landscape structure variables (in RDA1, longer blue

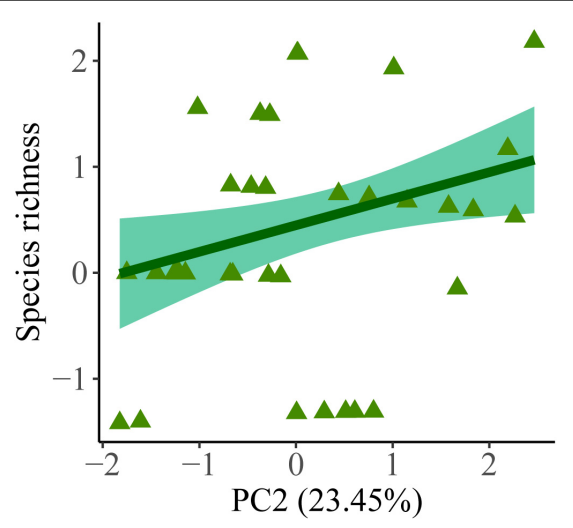

FIGURE 3 | Final regression model revealing the effect of habitat quality in small mammal estimated species richness (Chao 1) for forest specialists in semideciduous forest patches in the Brazilian Cerrado. PC2 corresponds to the second axis of a principal component analysis of six forest structure variables used to describe habitat quality.

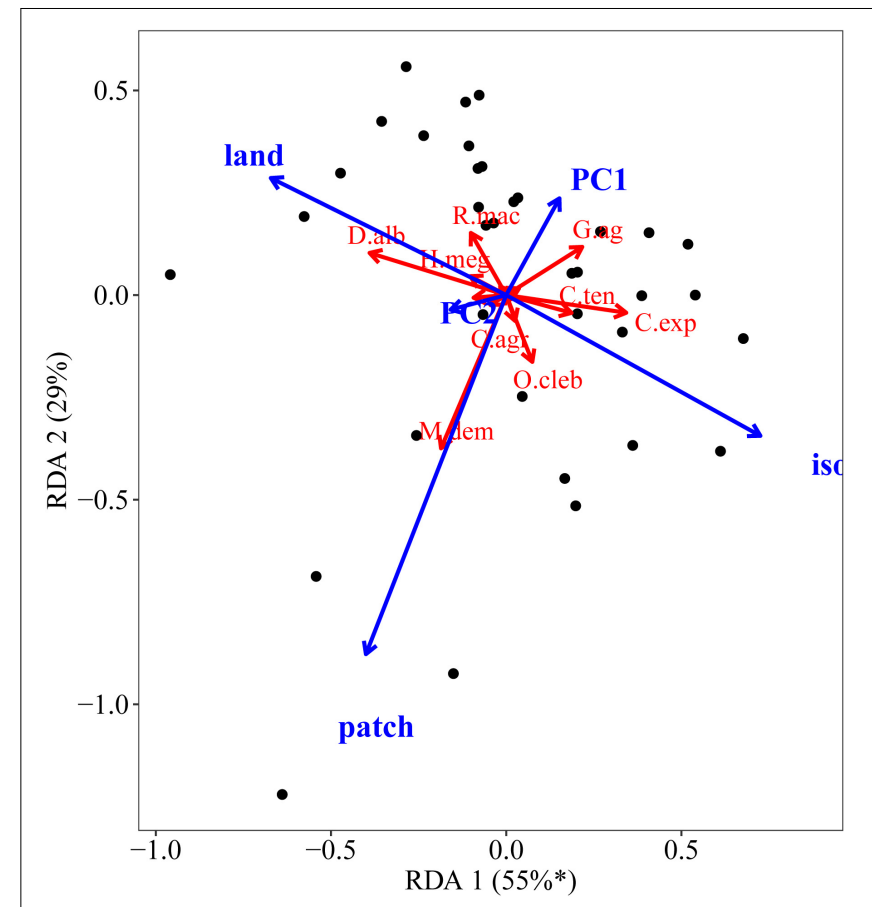

FIGURE 4 | RDA triplot (Scaling 2 method - correlation plot) showing the relationship between small mammal species composition, landscape structure [patch area (patch), patch isolation (iso), and proportion of habitat amount in the landscape (land)], and habitat quality (PC1 and PC2 corresponding to the first and second axis of a principal component analysis of six forest structure variables used to describe habitat quality) in semideciduous forest patches in the Brazilian Cerrado. Species are shown in red: Calomys expulsus (C.exp), C. tener (C.ten), Cryptonanus agricolai (C.agr), Didelphis albiventris (D.alb), Gracilinanus agilis (G.ag), Hylaeamys megacephalus (H.mega), Marmosa demerarae (M.dem), O. cleberi (O.cleb), and Rhipidomys macrurus (R.mac). Sampling sites are represented by black dots.

arrows with greater projections on this axis) were much more important to explain the variation in species composition of the sampling sites than habitat quality features. From negative to positive values of the RDA1 axis, a clear gradient of patch size, isolation and habitat amount emerged: from larger patches, inserted in landscapes with higher amounts of habitat, toward smaller and isolated patches located in more degraded landscapes. Additionally, we could also observe that there were species clearly correlated with these explanatory variables (indicated by longer red arrows with greater right-angled projections on the RDA1 axis): Didelphis was associated with higher amounts of forest cover in the landscape. The marsupial $M$. demerarae was highly related to larger patches, irrespective to forest cover in the landscape. On the other hand, G. agilis showed great association with smaller patches, independently of habitat amount. The generalist rodents C. expulsus and C. tener were highly associated with more deforested landscapes and with isolated patches, but not with patch size. Oecomys cleberi was also related with less habitat amount in the landscape. The other species were gathered together in the center of the plot, apparently not influenced by the evaluated predictors. The following species were omitted for obtaining a better 
visual aspect in the plot, since they displayed no correlation with evaluated predictors: M. murina, Oecomys catherinae, Oligoryzomys mattogrossae, O. moojeni, O. nigripes, and Rattus rattus.

\section{DISCUSSION}

Contrary to our expectations, we did not find any patch size effects depending on landscape habitat amount on abundance, richness, or taxonomic and functional diversity, regardless of the level of habitat specificity. However, habitat generalists and forest specialists responded differently to the isolated effects of patch size and habitat amount, and only specialist richness was affected by habitat quality. Furthermore, small mammal diversity metrics did not respond to either landscape structure or habitat quality.

Contradicting our hypothesis, the abundance of habitat generalists and forest specialists responded negatively to patch size, indicating that smaller patches held higher overall small mammal abundance. However, only generalists responded to the proportion of habitat amount in the landscape, being more abundant in more deforested landscapes, according to the findings of Pardini et al. (2010) for generalists in the Atlantic Forest. For habitat generalists, this pattern was also found by Melo (2015) in woodland savannas in the Cerrado. As for the abundance of forest specialists, she only found a negative effect of patch size in intermediate landscapes (30\% of habitat amount), while specialists were more abundant according to higher forest cover in the landscape. In the Amazon, an increase of small mammal abundance with the reduction of forest area was also registered (Palmeirim et al., 2020).

The overall increase in species abundances (for generalists and forest specialists), which we found in smaller patches, might be linked to several ecological processes. First, to some extent, we believe that an ecological release from predators such as medium-sized mammals, raptors, owls and snakes, might be taking place. These are important predators of small mammals, and can suffer negatively with fragmentation and habitat loss (Carrete et al., 2009; Fenker et al., 2014; Rocha et al., 2018). Additionally, there might be a competition release effect due to the defaunation of large seed-predator mammals (Dirzo et al., 2014; Galetti et al., 2015a). It has been observed that defaunated forests showed an increase in the abundance of small seedpredators, specially rodents (Galetti et al., 2015b). Moreover, but to a lesser extent, forest invasion by matrix-tolerant species (for example, belonging to the genus Calomys) can contribute to the observed increase in abundance of habitat generalists in smaller fragments and in more eroded landscapes, which is probably linked to higher edge effects (Pardini, 2004; Santos-Filho et al., 2008). Also, in our study, a major increase in abundance of habitat generalists, mainly in smaller patches, might be an effect of a higher abundance of the dominant species Gracilinanus agilis, which represented almost $64 \%$ of all captures.

Finding no patch size or isolation effects either for forest specialist or generalist species richness, but identifying an effect of habitat amount at the landscape scale (even though for generalist species only) suggests that landscape vegetation cover is a better predictor of species richness than patch size and patch isolation. This landscape effect was proposed by Fahrig (2013) in the Habitat Amount Hypothesis, later tested and confirmed by Melo et al. (2017) for overall small mammal richness in woodland savannas in the Brazilian Cerrado, as well as for other animal groups (Garmendia et al., 2013; Ikin et al., 2014; ArroyoRodríguez et al., 2016). Landscape-scale responses might vary among ecosystems, with the level of habitat specificity of the studied species (Pardini et al., 2010; Melo, 2015), with the quality of the matrix habitat, an important feature of landscape-mediated processes, which can severely impact animal movements across the landscape, and influence colonization/extinction rates among patches (Palmeirim et al., 2020).

In fragmented landscapes, higher amounts of habitat should reduce overall patch isolation (Pardini et al., 2010), increasing inter-patch connectivity, and favoring movements of certain species between patches (Vieira et al., 2009). In this context, matrix type and finer-scale matrix elements such as scattered trees should play an important role in determining which species can succeed in moving through the matrix between patches (Prevedello and Vieira, 2010; Garmendia et al., 2013; Muanis, 2017). Structurally simplified matrices, such as the dominant pasture matrix in our study, might be more impermeable for forest specialists than for habitat generalists, since matrix type effects depend on species-specific habitat requirements, and matrix quality is linked to patch structure similarity (Prevedello and Vieira, 2010; Arroyo-Rodríguez et al., 2016). In this sense, our findings on the relationship between generalist species richness and habitat amount should be expected. Moreover, the lack of an effect of habitat amount for specialists, contrary to the findings from other studies (Pardini et al., 2010; Melo, 2015), also indicates that in our study system there might be more important factors influencing species richness than spatial structure; or there might be other non-evaluated landscape predictors of biodiversity such as landscape heterogeneity. In highly fragmented savanna landscapes immersed in agricultural mosaics, landscape heterogeneity was a better preditor of taxonomic diversity than habitat amount for non-breeding birds (Ke et al., 2018).

In altered landscapes, habitat conditions inside patches (i.e., patch quality) might be equally or more important than spatial structure of the landscape to determine assemblages (Ikin et al., 2014; Delciellos et al., 2016; Zimbres et al., 2017; Palmeirim et al., 2020), since habitat quality features may be more closely related to the consequences of fragmentation on ecosystems (Ikin et al., 2014). This way, habitat degradation resulting from fragmentation can have a more important deleterious effect on species persistence in fragments, reducing species richness, mainly of forest specialists (Zimbres et al., 2017).

Indeed, in our study, habitat quality features predicted specialist species richness, indicating that forests with higher canopy cover harbored more species. A more closed canopy cover suggests higher levels of forest integrity, or more structured forests. Fragmentation leads to the mortality of large trees (as a consequence of increased desiccation at edges, associated with secondary causes such as more frequent fire events and logging activity), which can reduce canopy cover, the presence of emergent species, volume of trees, and 
consequently forest structural complexity (Laurence et al., 2000). Structural complexity offers more opportunities for species coexistence, leading to vertical niche stratification of small mammals, increasing species turnover among forest strata, and consequently enhancing richness (Camargo et al., 2018). Our findings reinforce the relative importance of patch forest quality compared to spatial structure for maintaining specialist species, which require more complex forests to persist in a fragmented landscape.

We failed to detect any effects of landscape structure or habitat quality on taxonomic or functional diversity. Responses of animal diversity to landscape structure are rather idiosyncratic: several studies identified positive patch size effects for small mammal taxonomic (Melo, 2015; Bovendorp et al., 2019) and functional diversity (Melo, 2015; Zimbres et al., 2017; Bovendorp et al., 2019), while others failed to find these effects on the same diversity dimensions (Palmeirim et al., 2020; Sancha et al., 2020; Smith et al., 2020). In much the same way, forest cover (i.e., habitat amount in the landscape) did not affect functional diversity of Atlantic forest small mammals (Sancha et al., 2020), while being an important predictor for forest-dependent frog species in the same biome (Almeida-Gomes et al., 2019). Bovendorp et al. (2019) suggested that, besides species-area effects, ecological interactions of predation or competition represented by the occurrence of medium and large-sized mammals should contribute to the retention of species and functional diversity of small mammal communities in the Atlantic Forest. On the other hand, small mammal functional diversity might be better predicted by non-evaluated landscape metrics more adequate for the spatial scale of response of small vertebrates, such as landscape heterogeneity. Conversely, temperature variables, rather than landscape structure, may determine functional diversity for small vertebrates (Sancha et al., 2020).

Finally, small mammal species composition has been strongly influenced by fragmentation and habitat loss, leading to marked species turnover with the reduction of specialist species and increased dominance of generalist species (Vieira et al., 2009; Pardini et al., 2010; Banks-leite et al., 2012; Garmendia et al., 2013; Melo, 2015; Palmeirim et al., 2020). Habitat quality inside patches related to landscape alterations have also been indicated as important predictors of change in species composition (Melo, 2015; Delciellos et al., 2016; Hannibal et al., 2018, 2020). However, our results showed that landscape structure variables (patch size, isolation, and proportion of habitat amount in the landscape) were the major drivers of changes in small mammal species composition relative to habitat quality features in semideciduous forests in the Brazilian savanna.

Surprisingly, Didelphis albiventris was the only species associated with higher amounts of forest cover in the landscape. Even though the genus Didelphis is considered a habitat generalist, apparently it also depends on higher forest cover at the patch (Santos-Filho et al., 2008) or landscape scale. In addition, $D$. marsupialis showed declining occupancy probability in more degraded forests in the Amazon Forest (Zimbres, 2016). These results suggest that even common and generalist species might have minimum habitat requirements to persist in humanmodified landscapes.
Marmosa demerarae, one of the rarest species in our study, on the other hand, was related to large patches, irrespective of the surrounding proportion of habitat amount. In the Atlantic Forest it was associated with forest edges and to a secondary forest matrix (Pardini, 2004), and reproductive males were able to travel among patches across a matrix composed by tall grasses, shrubs, and scattered trees (Pires et al., 2002). On the other hand, SantosFilho et al. (2008) registered high abundance of this species in the interior of forest patches, while it was never captured in the pasture matrix. Matrix use is thus apparently highly dependent on matrix quality, which explain these variations in abundance and responses to edge effects and matrix permeability found in other studies. Our results indicated that $M$. demerarae is a sensitive species to fragmentation in the Brazilian Cerrado, and this sensitiveness might be affected by the quality of the surrounding matrix.

Conversely, G.agilis, the dominant species in our study, was strongly associated with smaller patches, independently of landscape vegetation cover. This abundant and generalist species has been indicated to be less susceptible to habitat fragmentation, not suffering from edge effects (Santos-Filho et al., 2008), and responding negatively to patch size (Cáceres et al., 2010). Also, it has been positively associated with the number of lianas, a proxy for forest disturbance (Campbell et al., 2015; Hannibal et al., 2018).

The rodents C. expulsus and C. tener were more associated with deforested landscapes and patch isolation, but were not influenced by patch size. In the Cerrado, the genus Calomys include common inhabitants of open areas such as grasslands and savannas (Marinho-Filho et al., 2002). However, they can also be equally present in forest edges and inside forest patches in fragmented landscapes, as well as in the pasture matrix (SantosFilho et al., 2008). They have been positively associated with environmental disturbances such as fire (Vieira, 1999), and also with lower forest NDVI, indicating a relationship with lower levels of forest integrity (Hannibal et al., 2018).

Lastly, Oecomys cleberi was negatively associated to forest cover in the landscape. Thus, this species might be sensitive to small patches but may tolerate some level of forest disturbance at larger scales. In fact, Oecomys genus apparently is less affected by edge effects (Santos-Filho et al., 2008), but still not be able to use pasture matrix, which might represent a barrier to dispersal. The genus apparently includes species that are dependent on resources available inside resident patches. Additionally, the congener O. bicolor was positively related to canopy cover and to NDVI (Hannibal et al., 2018) in semideciduous forests in the Cerrado, indicating demands for better conditions of forest structure, which is usually not the case for smaller patches (Laurence et al., 2000).

The above mentioned results suggest that species responses to landscape changes may not only be necessarily guild-specific or associated to the degree of habitat specialization of the taxa, but be species-specific, being mediated by other ecological and behavioral traits (Caruso et al., 2016; Heim et al., 2019) related to reproduction, life-cycle, body size and dispersal hability (Blanchet et al., 2010; Farneda et al., 2015; Lecoq et al., 2021).

Contradicting our expectations, the results of this work indicated that the effect of landscape configuration did not 
depend on the proportion of habitat amount in the landscape to determine small mammal assemblages, as found in other studies in the Brazilian Cerrado (Melo, 2015) and in the Atlantic Forest (Pardini et al., 2010). However, both landscape structure characteristics analyzed impacted different aspects of assemblages and in distinct ways. Reduction in patch size was mainly linked to an overall increase in small mammal abundance, while habitat generalist species richness was determined by habitat amount in the landscape. This result reinforces that habitat amount should be a better predictor of species richness than patch size, as proposed by Fahrig (2013) and confirmed to taxa such as small mammals (Melo et al., 2017) and birds (De Camargo et al., 2018). On the other hand, specialist richness was only influenced by forest quality inside patches, suggesting that species with higher habitat requirements might respond to fragmentation and habitat loss at finer scales. In this sense, our study demonstrated the importance to address habitat quality changes in landscape research (Delciellos et al., 2016), in order to better understand the consequences of fragmentation and habitat loss in ecosystems, which will depend on the species in question and their habitat requirements. Lastly, we failed to detect any effect of either landscape structure or habitat quality on the other diversity dimensions.

In the face of current high rates of deforestation and conversion of natural landscapes into croplands and pastures in the Brazilian Cerrado (Alencar et al., 2020), associated with low levels of compliance with environmental legislation (Fearnside, 2001; Strassburg et al., 2017), it is essential to generate guidelines and more effective policies for conservation and restoration plans focused on landscape remnants in the world's richest savanna (Faleiro et al., 2013). In this context, our study showed that landscapes with higher vegetation cover should be more effective for protecting habitat generalist species, while preserving the integrity of remnants should benefit forest specialists. Therefore, we suggest that landscape management actions prioritize setting aside and/or restoring existing legal reserves in a way that maximizes forest cover at the landscape scale. This should be planned and executed by coordinating efforts among landholders, as also suggested by Zimbres et al. (2017). Additionally, we reinforce that conserving biodiversity requires the restoration and maintenance of habitat quality of forest remnants, which has been neglected by current environmental policies. Among the management actions that should contribute to more structurally sound forests within reserves are: avoiding cattle intrusion, protecting remnants from wildfires, and avoiding selective logging (Gerwing, 2002; Vieira and Scariot, 2006; Piana and Marsden, 2014).

Furthermore, we propose that future studies should investigate the impacts of shifting species interactions (predators and competitors) on the community dynamics, since defaunation is apparently a strong driver of change in abundance and diversity of small mammals in altered landscapes (Galetti et al., 2015b; Bovendorp et al., 2019), which in turn has profound consequences in ecosystems (Dirzo et al., 2014; Soares et al., 2015; Marjakangas et al., 2020). We also suggest evaluating the effects of the matrix structure, quality, and landscape heterogeneity (Fahrig et al., 2011; Reynolds et al., 2017; Ke et al., 2018) in the studies seeking to better understand the dynamics of species and populations surviving in fragmented landscapes.

\section{DATA AVAILABILITY STATEMENT}

The original contributions presented in the study are included in the article/Supplementary Material, further inquiries can be directed to the corresponding author.

\section{ETHICS STATEMENT}

The animal study was reviewed and approved by Committee of Ethics and Animal Use from the Universidade de Brasília (18/2018 CEUA-UnB).

\section{AUTHOR CONTRIBUTIONS}

IM conceived and designed the study, conducted data collection and data analysis, and drafted the manuscript. BZ contributed to the study design, performed spatial analysis, and contributed to the writing of the manuscript. JM-F contributed to the study design and supervised the work. All authors critically revised the manuscript.

\section{FUNDING}

This project was supported by Rufford Small Grants Foundation (24992-1), the American Society of Mammalogists (ASM, Latin American Student Field Research Award 2019), and Decanato de Pesquisa e Pós-Graduação da Universidade de Brasília (DPGUnB). Coordenação de Aperfeiçoamento de Pessoal de Nível Superior (CAPES) provided a Ph.D. scholarship to IM. Fundação de Amparo à Pesquisa do Distrito Federal (FAPDF - 1378/2016) and Brazilian Science Council (CNPq) provided research grants to JM-F that helped to support fieldwork.

\section{ACKNOWLEDGMENTS}

This project was part of the Ph.D. thesis in Zoology of IM (Mattos, 2020). We conducted the study with a license from Instituto Chico Mendes de Biodiversidade (SISBIO 61990) and the Secretaria de Meio Ambiente do Estado de Goiás (SECIMA/CEMan 006/2019). We thank all the field assistants that took part in data collection, especially Arthur Rodrigues, Gabriel Amaral, and Jaíne Andrade. We also thank landowners for the permission to access forest remnants inside their landholdings, as well as for logistical support, and Danilo Fortunato for valuable comments on the analyses.

\section{SUPPLEMENTARY MATERIAL}

The Supplementary Material for this article can be found online at: https://www.frontiersin.org/articles/10.3389/fevo.2021. 751315/full\#supplementary-material 


\section{REFERENCES}

Alencar, A., Shimbo, J. Z., Lenti, F., Marques, C. B., Zimbres, B., Rosa, M., et al. (2020). Mapping three decades of changes in the brazilian savanna native vegetation using landsat data processed in the google earth engine plataform. Remote Sens. 924, 1-23. doi: 10.3390/rs12060924

Almeida-Gomes, M., Vieira, M. V., Rocha, C. F. D., and Melo, A. S. (2019). Habitat amount drives the functional diversity and nestedness of anuran communities in an Atlantic Forest fragmented landscape. Biotropica 51, 874-884. doi: 10. 1111/btp.12687

Andreas, M., Reiter, A., Cepáková, E., and Uhrin, M. (2013). Body size as an important factor determining trophic niche partitioning in three syntopic rhinolophid bat species. Biologia 68, 170-175. doi: 10.2478/s11756-0120139-1

Andren, H. (1994). Effects of habitat fragmentation onbirds and mammals in landscapes with different proportions of suitable habitat: a review. Oikos 71, 355-366.

Arroyo-Rodríguez, V., Rojas, C., Saldaña-Vázquez, R. A., and Stoner, K. E. (2016). Landscape composition is more important than landscape configuration for phyllostomid bat assemblages in a fragmented biodiversity hotspot. Biol. Conserv. 198, 84-92. doi: 10.1016/j.biocon.2016.03.026

Banks-leite, C., Ewers, R. M., and Metzger, J. P. (2012). Unraveling the drivers of community dissimilarity and species extinction in fragmented landscapes. Ecology 93, 2560-2569.

Bates, D., Mächler, M., Bolker, B., and Walker, S. (2015). Fitting linear mixed-effects models using lme4. J. Stat. Softw. 67, 1-48.

Bergallo, H. G., and Magnusson, W. E. (1999). Effects of climate and food availability on four rodent species in Southeastern Brazil. J. Mammal. 80, 472-486. doi: 10.2307/1383294

Bezerra, A. M. R., Carmignotto, A. P., and Rodrigues, F. H. G. (2009). Small non-volant mammals of an ecotone region between the cerrado hotspot and the amazonian rainforest, with comments on their taxonomy and distribution. Zool. Stud. 48, 861-874.

Bisceglia, S. B. C., Pereira, J. A., Teta, P., and Quintana, R. D. (2011). Rodent selection by Geoffroy's cats in a semi-arid scrubland of central Argentina. J. Arid Environ. 75, 1024-1028. doi: 10.1016/j.jaridenv.2011.03.016

Blanchet, S., Rey, O., Etienne, R., Lek, S., and Loot, G. (2010). Species-specific responses to landscape fragmentation: implications for management strategies. Evol. Appl. 3, 291-304. doi: 10.1111/j.1752-4571.2009.00110.x

Bonvicino, C. R., Lindbergh, S. M., and Maroja, L. S. (2002). Small non-flying mammals from conserved and altered areas of atlantic forest and cerrado: comments on their potential use for monitoring environment. Brazilian J. Biol. 62, 765-774. doi: 10.1590/S1519-69842002000500005

Borcard, D., Gillet, F., and Legendre, P. (2011). Numerical Ecology with R. New York, NY: Springer.

Botta-Dukát, Z. (2005). Rao's quadratic entropy as a measure of functional diversity based on multiple traits. J. Veg. Sci. 16, 533-540. doi: 10.1111/j.1654-1103.2005. tb02393.x

Bovendorp, R. S., Brum, F. T., McCleery, R. A., Baiser, B., Loyola, R., Cianciaruso, M. V., et al. (2019). Defaunation and fragmentation erode small mammal diversity dimensions in tropical forests. Ecography (Cop.). 42, 23-35. doi: 10. 1111/ecog.03504

Brown, J. H., Whitham, T. G., Morgan Ernest, S. K., and Gehring, C. A. (2001). Complex species interactions and the dynamics of ecological systems: long-term experiments. Science 293, 643-650. doi: 10.1126/science.293.5530.643

Cáceres, N. C., Nápoli, R. P., Casella, J., and Hannibal, W. (2010). Mammals in a fragmented savannah landscape in south-western Brazil. J. Nat. Hist. 44, 491-512. doi: 10.1080/00222930903477768

Cadotte, M. W., Carscadden, K., and Mirotchnick, N. (2011). Beyond species: functional diversity and the maintenance of ecological processes and services. J. Appl. Ecol. 48, 1079-1087. doi: 10.1111/j.1365-2664.2011.02048.x

Camargo, N. F., de Gurgel-Gonçalves, R., and Palma, A. R. T. (2008). Variação morfológica de pegadas de roedores arborícolas e cursoriais do Cerrado. Rev. Bras. Zool. 25, 696-704. doi: 10.1590/s0101-81752008000400015

Camargo, N. F., de Oliveira, H. F. M., Ribeiro, J. F., de Camargo, A. J. A., and Vieira, E. M. (2019a). Availability of food resources and habitat structure shape the individual-resource network of a Neotropical marsupial. Ecol. Evol. 9, 3946-3957. doi: 10.1002/ece3.5024
Camargo, N. F., Machado, L. F., Mendonça, A. F., and Vieira, E. M. (2019b). Cranial shape predicts arboreal activity of Sigmodontinae rodents. J. Zool. 308, 128-138. doi: 10.1111/jzo.12659

Camargo, N. F., De Sano, N. Y., and Vieira, E. M. (2018). Forest vertical complexity affects alpha and beta diversity of small mammals. J. Mammal. 99, 1444-1454. doi: 10.1093/jmammal/gyy136

Campbell, M., Laurance, W. F., and Magrach, A. (2015). "Ecological Effects of Lianas in Fragmented Forests," in Ecology of Lianas, eds S. A. Schnitzer, F. Bongers, R. J. Burnham, and F. E. Putz (Queensland, Qld: John Wiley \& Sons, Ltd), 443-450.

Carrete, M., Tella, J. L., Blanco, G., and Bertellotti, M. (2009). Effects of habitat degradation on the abundance, richness and diversity of raptors across Neotropical biomes. Biol. Conserv. 142, 2002-2011. doi: 10.1016/j.biocon.2009. 02.012

Caruso, N., Lucherini, M., Fortin, D., and Casanave, E. B. (2016). Species-specific responses of carnivores to human induced landscape changes in Central Argentina. PLoS One 11:e0150488. doi: 10.1371/journal.pone.0150488

Colwell, R. K., Chao, A., Gotelli, N. J., Lin, S. Y., Mao, C. X., Chazdon, R. L., et al. (2012). Models and estimators linking individual-based and sample-based rarefaction, extrapolation and comparison of assemblages. J. Plant Ecol. 5, 3-21. doi: 10.1093/jpe/rtr044

de Bello, F., Lavorel, S., Díaz, S., Harrington, R., Cornelissen, J. H. C., Bardgett, R. D., et al. (2010). Towards an assessment of multiple ecosystem processes and services via functional traits. Biodivers. Conserv. 19, 2873-2893. doi: 10.1007/ s10531-010-9850-9

De Camargo, R., Boucher-Lalonde, V., and Currie, D. J. (2018). At the landscape level, birds respond strongly to habitat amount but weakly to fragmentation. Divers. Distrib. 24, 1-11. doi: 10.1111/ddi.12706

Delciellos, A. C., De Barros, C. S., Prevedello, J. A., Ferreira, M. S., Cerqueira, R., and Vieira, M. V. (2018). Habitat fragmentation affects individual condition: evidence from small mammals of the Brazilian Atlantic Forest. J. Mammal. 99, 936-945. doi: 10.1093/jmammal/gyy078

Delciellos, A. C., Vieira, M. V., Grelle, C. E. V., Cobra, P., and Cerqueira, R. (2016). Habitat quality versus spatial variables as determinants of small mammal assemblages in Atlantic Forest fragments. J. Mammal. 97, 253-265. doi: 10. 1093/jmammal/gyv175

Dias, A. T. C., Berg, M. P., de Bello, F., Van Oosten, A. R., Bílá, K., and Moretti, M. (2013). An experimental framework to identify community functional components driving ecosystem processes and services delivery. J. Ecol. 101, 29-37. doi: 10.1111/1365-2745.12024

Dirzo, R., Young, H. S., Galetti, M., Ceballos, G., Isaac, N. J. B., and Collen, B. (2014). Defaunation in the Anthropocene. Science 345, 401-406. doi: 10.1126/ science. 1251817

Eisenberg, J. F., and Wilson, D. E. (1981). Relative brain size and demographic strategies in didelphid marsupials. Am. Nat. 118, 1-15. doi: 10.1086/283796

Fahrig, L. (2003). Effects of habitat fragmentation on biodiversity. Annu. Rev. Ecol. Evol. Syst. 34, 487-515. doi: 10.1146/annurev.ecolsys.34.011802.132419

Fahrig, L. (2013). Rethinking patch size and isolation effects: the habitat amount hypothesis. J. Biogeogr. 40, 1649-1663. doi: 10.1111/jbi.12130

Fahrig, L., Baudry, J., Brotons, L., Burel, F. G., Crist, T. O., Fuller, R. J., et al. (2011). Functional landscape heterogeneity and animal biodiversity in agricultural landscapes. Ecol. Lett. 14, 101-112. doi: 10.1111/j.1461-0248.2010.01559.x

Faleiro, F. V., Machado, R. B., and Loyola, R. D. (2013). Defining spatial conservation priorities in the face of land-use and climate change. Biol. Conserv. 158, 248-257. doi: 10.1016/j.biocon.2012.09.020

Farneda, F. Z., Rocha, R., López-Baucells, A., Groenenberg, M., Silva, I., Palmeirim, J., et al. (2015). Trait-related responses to habitat fragmentation in Amazonian bats. J. Appl. Ecol. 52, 1381-1391. doi: 10.1111/1365-2664.12490

Fearnside, P. M. (2001). Soybean cultivation as a threat to the environment in Brazil. Environ. Conserv. 28, 23-38. doi: 10.1017/S0376892901000030

Fenker, J., Tedeschi, L. G., Pyron, R. A., Nogueira, C., and De, C. (2014). Phylogenetic diversity, habitat loss and conservation in South American pitvipers (Crotalinae: Bothrops and Bothrocophias). Divers. Distrib. 20, 11081119. doi: 10.1111/ddi.12217

Françoso, R. D., Brandão, R., Nogueira, C. C., Salmona, Y. B., Machado, R. B., and Colli, G. R. (2015). Habitat loss and the effectiveness of protected areas in the Cerrado Biodiversity Hotspot. Nat. Conserv. 13, 35-40. doi: 10.1016/j.ncon. 2015.04.001 
Freitas, J. R., and Mantovani, W. (2018). An overview of the applicability of functional diversity in biological conservation. Brazilian J. Biol. 78, 517-524. doi: 10.1590/1519-6984.09416

Galetti, M., Bovendorp, R. S., and Guevara, R. (2015a). Defaunation of large mammals leads to an increase in seed predation in the Atlantic forests. Glob. Ecol. Conserv. 3, 824-830. doi: 10.1016/j.gecco.2015.04.008

Galetti, M., Guevara, R., Neves, C. L., Rodarte, R. R., Bovendorp, R. S., Moreira, M., et al. (2015b). Defaunation affect population and diet of rodents in Neotropical rainforests. Biol. Conserv. 190, 2-7. doi: 10.1016/j.biocon.2015.04.032

Galleti, M., Pardini, R., Duarte, J. M. B., Silva, V. M. F., Rossi, A., and Peres, C. A. (2010). Mudanças no Código Florestal e seu impacto na ecologia e diversidade de mamíferos no Brasil. Biota Neotrop. 10, 47-52. doi: 10.1177/ 004051757604601207

Gámez-Virués, S., Perović, D. J., Gossner, M. M., Börschig, C., Blüthgen, N., De Jong, H., et al. (2015). Landscape simplification filters species traits and drives biotic homogenization. Nat. Commun. 6, 1-8. doi: 10.1038/ncomms9568

Garmendia, A., Arroyo-Rodríguez, V., Estrada, A., Naranjo, E. J., and Stoner, K. E. (2013). Landscape and patch attributes impacting medium- and large-sized terrestrial mammals in a fragmented rain forest. J. Trop. Ecol. 29, 331-344. doi: $10.1017 /$ S0266467413000370

Gerwing, J. J. (2002). Degradation of forest through logging and fire in the eastern Brazilian Amazon. For. Ecol. Manag. 157, 131-141. doi: 10.1016/S03781127(00)00644-7

Gibbs, H. K., Ruesch, A. S., Achard, F., Clayton, M. K., Holmgren, P., Ramankutty, N., et al. (2010). Tropical forests were the primary sources of new agricultural land in the 1980s and 1990s. Proc. Natl. Acad. Sci. U.S.A. 107, 16732-16737. doi: 10.1073/pnas.0910275107

Gomes, L., de, P., Rocha, C. R., Brandão, R. A., and Marinho-Filho, J. (2015). Mammal richness and diversity in Serra do Facão region, southeastern goiás state, central Brazil. Biota Neotrop. 15, 1-11. doi: 10.1590/1676-0611-BN-20150033

Haddad, N. M., Brudvig, L. A., Clobert, J., Davies, K. F., Gonzalez, A., Holt, R. D., et al. (2015). Habitat fragmentation and its lasting impact on Earth's ecosystems. Sci. Adv. 1:e1500052. doi: 10.1126/sciadv.1500052

Hannibal, W., Cunha, N. L., Da Figueiredo, V. V., Rossi, R. F., Cáceres, N. C., and Ferreira, V. L. (2018). Multi-scale approach to disentangle the small mammal composition in a fragmented landscape in central Brazil. J. Mammal. 99, 1455-1464. doi: 10.1093/jmammal/gyy142

Hannibal, W., Cunha, N. L., Da Figueiredo, V. V., Teresa, F. B., and Ferreira, V. L. (2020). Traits reveal how habitat-quality gradients strucuture small mammal communities in a fragmented tropical landscape. Austral Ecol. 45, 79-88.

Hanski, I. (2015). Habitat fragmentation and species richness. J. Biogeogr. 42, 989-993. doi: 10.1111/jbi.12478

Heim, N., Fisher, J. T., Volpe, J., Clevenger, A. P., and Paczkowski, J. (2019). Carnivore community response to anthropogenic landscape change: speciesspecificity foils generalizations. Lanscape Ecol. 34, 2493-2507. doi: 10.1007/ s10980-019-00882-z

Hirt, M. R., Jetz, W., Rall, B., and Brose, U. (2017). A general scaling law reveals why the largest animals are not the fastest. Nature. 1, 1116-1122.

Ikin, K., Barton, P. S., Stirnemann, I. A., Stein, J. R., Michael, D., Crane, M., et al. (2014). Multi-scale associations between vegetation cover and woodland bird communities across a large agricultural region. PLoS One 9:e97029. doi: 10.1371/journal.pone.0097029

Jost, L. (2006). Entropy and diversity. Oikos 113, 363-375. doi: 10.1111/j.2006. 0030-1299.14714.x

Kajin, M., and Grelle, C. E. V. (2012). Microhabitat selection when detection is imperfect: the case of an endemic Atlantic forest mammal. Ecol. Res. 27, 1005-1013. doi: 10.1007/s11284-012-0977-x

Ke, A., Sibiya, M. D., Reynolds, C., McCleery, R. A., Monadjem, A., and Fletcher, R. J. Jr. (2018). Landscape heterogeneity shapes taxonomic diversity of nonbreeding birds across fragmented savanna landscapes. Biodivers. Conserv. 27, 2681-2698. doi: 10.1007/s10531-018-1561-7

Klink, C., Klink, C., Machado, R. B., and Machado, R. B. (2005). A conservação do Cerrado brasileiro. Megadiversidade 1, 147-155. doi: 10.1590/S010069912009000400001

Kotler, B. P., and Brown, J. S. (1988). Environmental heterogeneity and the coexistence of desert rodents. Annu. Rev. Ecol. Syst. 19, 281-307. doi: 10.1146/ annurev.es.19.110188.001433
Laliberté, A. E., Legendre, P., Shipley, B., and Laliberté, M. E. (2014). Package 'FD ': Measuring Functional Diversity From Multiple Traits, And Other Tools For Functional Ecology. R package version 1.0-1.2.

Laliberté, E., and Legendre, P. (2010). A distance-based framework for measuring functional diversity from multiple traits. Ecology 91, 299-305. doi: 10.1890/082244.1

Lande, R. (1987). Extinction thresholds in demographic models of territorial populations. Am. Nat. 130, 624-635.

Laurance, W. F., Camargo, J. L. C., Fearnside, P. M., Lovejoy, T. E., Williamson, G. B., Mesquita, R. C. G., et al. (2018). An Amazonian rainforest and its fragments as a laboratory of global change. Biol. Rev. 93, 223-247. doi: 10.1111/ brv. 12343

Laurance, W. F., Camargo, J. L. C., Luizão, R. C. C., Laurance, S. G., Pimm, S. L., Bruna, E. M., et al. (2011). The fate of Amazonian forest fragments: a 32-year investigation. Biol. Conserv. 144, 56-67. doi: 10.1016/j.biocon.2010. 09.021

Laurence, W. F., Vasconcelos, H. L., and Lovejoy, T. E. (2000). Forest loss and fragmentation in the Amazon: implications for wildlife conservation. Oryx 34, 39-45.

Lecoq, L., Ernoult, A., and Mony, C. (2021). Past landscape structure drives the functional assemblages of plants and birds. Sci. Rep. 11, 3443-3458. doi: 10. 1038/s41598-021-82851-8

Lesak, A. A., Radelof, V. C., Hawbaker, T. J., Pidgeon, A. M., Gobakken, T., and Contrucci, K. (2011). Modeling forest songbird species richness using LiDARderived measures of forest structure. Remote Sens. Environ. 115, 2823-2835. doi: 10.1016/j.rse.2011.01.025

MacMillen, R. E. (1983). Adaptive physiology of heteromyid rodents. Gt. Basin Nat. Mem. 7, 65-76.

Marinho-Filho, J., Rodrigues, F. H. G., and Juarez, K. M. (2002). "Mammals: diversity, ecology, and natural history," in The Cerrados of Brazil: Ecology and Natural History of a Neotropical Savanna, eds P. S. Oliveira and R. J. Marquis (New York, NY: Columbia University Press), 266-284.

Marjakangas, E. L., Abrego, N., Grøtan, V., de Lima, R. A. F., Bello, C., Bovendorp, R. S., et al. (2020). Fragmented tropical forests lose mutualistic plant-animal interactions. Divers. Distrib. 26, 154-168. doi: 10.1111/ddi.13010

Martensen, A. C., Ribeiro, M. C., Banks-Leite, C., Prado, P. I., and Metzger, J. P. (2012). Associations of forest cover, fragment area, and connectivity with Neotropical understory bird species richness and abundance. Conserv. Biol. 26, 1100-1111. doi: 10.1111/j.1523-1739.2012.01940.x

Martins, A. C., Willig, M. R., Presley, S. J., and Marinho-Filho, J. (2017). Effects of forest height and vertical complexity on abundance and biodiversity of bats in Amazonia. For. Ecol. Manage. 391, 427-435. doi: 10.1016/j.foreco.2017.02.039

Mattos, I. (2020). Resposta Dos Pequenos Mamíferos Do Cerrado À Fragmentação E Perda De Habitat: Uma Perspectiva Funcional E Trófica. PhD thesis, Brasília: Universidade de Brasília.

Melo, G. L. (2015). Effects of Habitat Loss And Fragmentation On Small Mammals In A Tropical South-American Savanna: An Ecological And Functional Approach. $\mathrm{PhD}$ thesis, Campo Grande: Universidade Federal de Mato Grosso do Sul.

Melo, G. L., Sponchiado, J., Cáceres, N. C., and Fahrig, L. (2017). Testing the habitat amount hypothesis for South American small mammals. Biol. Conserv. 209, 304-314. doi: 10.1016/j.biocon.2017.02.031

Miles, L., Newton, A. C., DeFries, R. S., Ravilious, C., May, I., Blyth, S., et al. (2006). A global overview of the conservation status of tropical dry forests. J. Biogeogr. 33, 491-505. doi: 10.1111/j.1365-2699.2005.01424.x

Mortelliti, A., Amori, G., and Boitani, L. (2010). The role of habitat quality in fragmented landscapes: a conceptual overview and prospectus for future research. Oecologia 163, 535-547. doi: 10.1007/s00442-010-1623-3

Muanis, M. (2017). Inter-patch Movements Of A Small Mammal And Implications For Functional Connectivity In A Fragmented Landscape. $\mathrm{PhD}$ thesis, Rio de Janeiro: Universidade Federal do Rio de Janeiro.

Murphy, P. G., and Lugo, A. E. (1986). Ecology of tropical dry forest. Annu. Rev. Ecol. Syst. 17, 67-88. doi: 10.1146/annurev.es.17.110186.000435

Myers, N., Mittermeler, R. A., Mittermeler, C. G., Da Fonseca, G. A. B., and Kent, J. (2000). Biodiversity hotspots for conservation priorities. Nature 403, 853-858. doi: 10.1038/35002501

Newmark, W. D., Stanley, W. T., and Goodman, S. M. (2014). Ecological correlates of vulnerability to fragmentation among Afrotropical terrestrial small mammals in northeast Tanzania. J. Mammal. 95, 269-275. doi: 10.1644/13-mamm-a-237 
Oksanen, A. J., Blanchet, F. G., Friendly, M., Kindt, R., Legendre, P., Mcglinn, D., et al. (2019). Package 'Vegan'. Available online at: https://cran.r-project.org/ package $=$ vegan $($ accessed November 6,2020$)$.

Olden, J. D., Poff, N. L. R., Douglas, M. R., Douglas, M. E., and Fausch, K. D. (2004). Ecological and evolutionary consequences of biotic homogenization. Trends Ecol. Evol. 19, 18-24. doi: 10.1016/j.tree.2003.09.010

Oliveira, J. A., and de Bonvicino, C. R. (2011). “Odem Rodentia," in Mamíferos do Brasil eds N. R. dos Reis, A. L. Peracchi, W. A. Pedro, and I. P. D. Lima (Londrina: Universidade de Brasília), 347-406.

Oliveira-Filho, A., and Ratter, J. (2002). "Vegetation physiognomies and woody flora of the cerrado biome," in The Cerrados of Brazil, eds P. S. Oliveira and R. J. Marquis (New York, NY: Columbia University Press), 91-120.

Paglia, A. P., Fonseca, G. A. B., Rylands, A. B., Herrmann, G., Aguiar, L. M. S., Chiarello, A. G., et al. (2012). Lista Anotada dos Mamíferos do Brasil/Annotated Checklist of Brazilian Mammals, 2a Edição/2nd Edn. Arlington County, VA: Conservation International.

Palmeirim, A. F., Santos-Filho, M., and Peres, C. A. (2020). Marked decline in forest-dependent small mammals following habitat loss and fragmentation in an Amazonian deforestation frontier. PLoS One 15:e0230209. doi: 10.1371/ journal.pone.0230209

Pardini, R. (2004). Effects of forest fragmentation on small mammals in an Atlantic Forest landscape. Biodivers. Conserv. 13, 2567-2586. doi: 10.1023/B: BIOC.0000048452.18878.2d

Pardini, R., Bueno, A., De, A., Gardner, T. A., Prado, P. I., and Metzger, J. P. (2010). Beyond the fragmentation threshold hypothesis: regime shifts in biodiversity across fragmented landscapes. PLoS One 5:e13666. doi: 10.1371/journal.pone. 0013666

Pardini, R., De Souza, S. M., Braga-Neto, R., and Metzger, J. P. (2005). The role of forest structure, fragment size and corridors in maintaining small mammal abundance and diversity in an Atlantic forest landscape. Biol. Conserv. 124, 253-266. doi: 10.1016/j.biocon.2005.01.033

Pavoine, S., and Bonsall, M. B. (2011). Measuring biodiversity to explain community assembly: a unified approach. Biol. Rev. 86, 792-812. doi: 10.1111/ j.1469-185X.2010.00171.x

Pebesma, E. J., and Bivand, R. S. (2005). Classes and methods for spatial data in R. $R$ News 5, 9-13.

Peres, C. A., Gardner, T. A., Barlow, J., Zuanon, J., Michalski, F., Lees, A. C., et al. (2010). Biodiversity conservation in human-modified Amazonian forest landscapes. Biol. Conserv. 143, 2314-2327. doi: 10.1016/j.biocon.2010.01.021

Petchey, O. L., and Gaston, K. J. (2006). Functional diversity: back to basics and looking forward. Ecol. Lett. 9, 741-758. doi: 10.1111/j.1461-0248.2006.00924.x

Piana, R. P., and Marsden, S. J. (2014). Impacts of cattle grazing on forest structure and raptor distribution within a neotropical protected area. Biodivers Conserv. 23, 559-572. doi: 10.1007/s10531-013-0616-Z

Pires, A. S., Lira, P. K., Fernandez, F. A. S., Schittini, G. M., and Oliveira, L. C. (2002). Frquency of movements of small mammals among Atlantic Coastal Forest fragments in Brazil. Biol. Conserv. 108, 229-237.

Podani, J., and Schmera, D. (2006). On dendrogram-based measures of functional diversity. Oikos 115, 179-185.

Prevedello, J. A., and Vieira, M. V. (2010). Does the type of matrix matter? A quantitative review of the evidence. Biodivers. Conserv. 19, 1205-1223. doi: 10.1007/s10531-009-9750-z

Previtali, M. A., Lima, M., Meserve, P. L., Kelt, D. A., and Gutiérrez, J. R. (2009). Population dynamics of two sympatric rodents in a variable environment: rainfall, resource availability, and predation. Ecology 90, 1996-2006.

Prieto-Torres, D. A., Nori, J., Rojas-Soto, O. R., and Navarro-Sigüenza, A. G. (2021). Challenges and opportunities in planning for the conservation of Neotropical seasonally dry forests into the future. Biol. Conserv. 257:109083. doi: 10.1016/j.biocon.2021.109083

R Core Team (2019). R: A Language And Environment For Statistical Computing. Available online at: http://www.r-project.org/ (accessed July 10, 2020).

Reynolds, C., Fletcher, Jr., R. J, Carneiro, C. M., Jennings, N., Ke, A., LaScaleia, M. C., et al. (2017). Inconsistent effects of landscape heterogeneity and landuse on animal diversity in na agricultural mosaic: a multi-scale and multi-taxon investigation. Landsc. Ecol. 33, 241-255. doi: 10.1007/s10980-017-0595-7

Ribeiro, J. F. (2015). Uso De Hábitat Em Diferentes Escalas, Distribuição Da Diversidade E Nicho Isotópico De Comunidades De Pequenos Mamíferos Do Cerrado Central. PhD thesis. Brasília: Universidade de Brasília.
Ribeiro, J. F., and Walter, B. M. T. (2008). “As principais fitofisionomias do bioma cerrado," in Cerrado: Ecologia E Flora, eds S. M. Sano, S. P. Almeida, and J. F. Ribeiro (Brasília: Embrapa), 151-212.

Ribeiro, J. F., Guardaldo, A., Nardoto, G. B., Santoro, G., and Vieira, E. V. (2019). Habitat type and seasonality influence the isotopic trophic niche of small mammals in a neotropical savanna. Hystrix It. J. Mammal. 30, 30-38.

Riofrío-Lazo, M., and Páez-Rosas, D. (2015). Feeding habits of introduced black rats, Rattus rattus, in nesting colonies of galapagos petrel on San Cristóbal Island, Galapagos. PLoS One 10:e0127901. doi: 10.1371/journal.pone.012 7901

Rocha, E. C., Brito, D., Silva, P. M. E., Silva, J., Bernardo, P. V., dos, S., et al. (2018). Effects of habitat fragmentation on the persistence of medium and large mammal species in the Brazilian Savanna of Goiás State. Biota Neotrop. 18:e20170483. doi: 10.1590/1676-0611-bn-2017-0483

Rossi, R. V., Bianconi, G. V., and Pedro, W. A. (2011). “Ordem didelphimorphia," in Mamíferos do Brasil, eds N. R. Reis, A. L. Peracchi, W. A. Pedro, and I. P. de Lima (Londrina: Universidade Estadual de Londrina), 27-66.

Sancha, N. U. D. La, Maestri, R., Bovendorp, R. S., and Higgins, C. L. (2020). Disentangling drivers of small mammal diversity in a highly fragmented forest system. Biotropica 52, 182-195. doi: 10.1111/btp.12745

Santos Filho, M., dos Da Silva, D. J., and Sanaiotti, T. M. (2008). Variação sazonal na riqueza e na abundância de pequenos mamíferos, na estrutura da floresta e na disponibilidade de artrópodes em fragmentos florestais no Mato Grosso, Brasil. Biota Neotrop. 8, 115-121. doi: 10.1590/S1676-06032008000100014

Santos-Filho, M., Da Silva, D. J., and Sanaiotti, T. M. (2008). Edge effects and landscape matrix use by a small mammal community in fragments of semideciduous submontane forest in Mato Grosso, Brazil. Brazilian J. Biol. 68, 703-710. doi: 10.1590/S1519-69842008000400004

Scariot, A., and Vieira, D. L. M. (2006). Principles of natural regeneration of tropical dry forests for restoration. Restor. Ecol. 14, 11-20.

Shiels, A. B., Pitt, W. C., Sugihara, R. T., and Witmer, G. W. (2014). Biology and impacts of pacific island invasive species Rattus rattus, the Black Rat (Rodentia: Muridae). Pacific Sci. 68, 145-184. doi: 10.2984/68.2.1

Sikes, R. S., and The Animal Care and Use Committee of the American Society of Mammalogists (2016). Guidelines of the American Society of Mammalogists for the use of wild mammals in research and education. J. Mammal. 97, 663-688. doi: 10.1093/jmammal/gyw078

Smith, Y. C. E., Smith, D. A., Ramesh, T., and Downs, C. T. (2020). Landscapescale drivers of mammalian species richness and functional diversity in forest patches within a mixed land-use mosaic. Ecol. Indic. 113:106176. doi: 10.1016/j. ecolind.2020.106176

Soares, L. A. S. S., Faria, D., Vélez-Garcia, F., Vieira, E. M., Talora, D. C., and Cazetta, E. (2015). Implications of habitat loss on seed predation and early recruitment of a keystone palm in anthropogenic landscapes in the brazilian atlantic rainforest. PLoS One 10:e0133540. doi: 10.1371/journal.pone.013 3540

Strassburg, B. B. N., Brooks, T., Feltran-barbieri, R., Iribarrem, A., Crouzeilles, R., Loyola, R., et al. (2017). Moment of truth for the Cerrado hotspot. Nat. Ecol. Evol. 1:0099. doi: 10.1038/s41559-017-0099

Tabarelli, M., and Gascon, C. (2005). Lessons from fragmentation research: improving management and policy guidelines for biodiversity conservation. Conserv. Biol. 19, 734-739. doi: 10.1111/j.1523-1739.2005.00698.x

Vieira, D. L. M., and Scariot, A. (2006). Principles of natural regeneration of Tropical Dry Forests for restoration. Restor. Ecol. 14, 11-20. doi: 10.1111/j. 1526-100X.2006.00100.x

Vieira, E. M. (1999). Small mammal communities and fire in the Brazilian Cerrado. J. Zool. 249, 75-81. doi: 10.1111/j.1469-7998.1999.tb01061.x

Vieira, E. M., and de Camargo, N. F. (2012). "Uso do espaço vertical por marsupiais brasileiros," in Os Marsupiais Do Brasil: Biologia, Ecologia E Conservação, ed. N. C. Cáceres (Campo Grande: UFMS), 347-366.

Vieira, M. V., Olifiers, N., Delciellos, A. C., Antunes, V. Z., Bernardo, L. R., Grelle, C. E. V., et al. (2009). Land use vs. fragment size and isolation as determinants of small mammal composition and richness in Atlantic Forest remnants. Biol. Conserv. 142, 1191-1200. doi: 10.1016/j.biocon.2009.02. 006

Villard, M. A., and Metzger, J. P. (2014). Beyond the fragmentation debate: a conceptual model to predict when habitat configuration really matters. J. Appl. Ecol. 51, 309-318. doi: 10.1111/1365-2664.12190 
Whitmee, S., and Orme, C. D. L. (2013). Predicting dispersal distance in mammals: a trait-based approach. J. Anim. Ecol. 82, 211-221. doi: 10.1111/j.1365-2656. 2012.02030.x

Wilson, M. C., Chen, X. Y., Corlett, R. T., Didham, R. K., Ding, P., Holt, R. D., et al. (2016). Habitat fragmentation and biodiversity conservation: key findings and future challenges. Landsc. Ecol. 31, 219-227. doi: 10.1007/s10980-0150312-3

With, K. A., and King, A. W. (1999). Dispersal success on fractal landscapes: a consequence of lacunarity thresholds. Landsc. Ecol. 14, 73-82. doi: 10.1023/A: 1008030215600

Zimbres, B. (2016). Áreas De Preservação Permanente Como Corredores Ecológicos Para A Fauna De Mamíferos De Médio E Grande Porte No Sul Da Amazônia. PhD thesis, Brasília: Universidade de Brasília.

Zimbres, B., Peres, C. A., and Machado, R. B. (2017). Terrestrial mammal responses to habitat structure and quality of remnant riparian forests in an Amazonian cattle-ranching landscape. Biol. Conserv. 206, 283-292. doi: 10.1016/j.biocon. 2016.11.033

Zuur, A. F., Ieno, E. N., and Smith, G. M. (2007). "Statistics for biology and health," in Analysing Ecological Data, eds M. Gail, K. Krickeberg, J. Samet, A. Tsiatis, and W. Wong (New York, NY: Springer).
Zuur, A. F., Ieno, E. N., Walker, N. J., Saveliev, A. A., and Smith, G. M. (2009) "Statistics for biology and health", in Mixed Effects Models and Extenstions in Ecology with R, eds M. Gail, K. Krickeberg, J. M. Samet, A. Tsiatis, and W. Wong (New York, NY: Springer).

Conflict of Interest: The authors declare that the research was conducted in the absence of any commercial or financial relationships that could be construed as a potential conflict of interest.

Publisher's Note: All claims expressed in this article are solely those of the authors and do not necessarily represent those of their affiliated organizations, or those of the publisher, the editors and the reviewers. Any product that may be evaluated in this article, or claim that may be made by its manufacturer, is not guaranteed or endorsed by the publisher.

Copyright (c) 2021 Mattos, Zimbres and Marinho-Filho. This is an open-access article distributed under the terms of the Creative Commons Attribution License (CC BY). The use, distribution or reproduction in other forums is permitted, provided the original author(s) and the copyright owner(s) are credited and that the original publication in this journal is cited, in accordance with accepted academic practice. No use, distribution or reproduction is permitted which does not comply with these terms. 